\title{
Islamabad, a town planning example for a sustainable city
}

\author{
I. M. Frantzeskakis \\ Emeritus National Technical University of Athens, \\ DENCO Development and Engineer Consultants, S.A., Athens, Greece
}

\begin{abstract}
Islamabad, the new Capital of Pakistan, planned by Constantinos A. Doxiadis and Doxiadis Associates in the late 1950s, is now a fast-growing city of about 1.5 million inhabitants, forming, together with the adjacent old city of Rawalpindi and a National Park, a Metropolitan Area (Greater Islamabad/Rawalpindi Area) of about 4.5 million inhabitants. This paper presents the combined land use-transportation planning of Islamabad, within the broader framework of the C.A. Doxiadis Ekistics theory. An evaluation of the results follows, based on a visit by the author and on more recent information.

The advantages of the clear hierarchy of residential communities, of the related functions and of the transport system are apparent in the segregation of the various categories of movements (i.e. high/low speed Road Traffic, Public Transport, Bicycles, Pedestrians, etc.) and in the reduction of trip lengths. They will be more and more apparent as the urban area expands and the population and car ownership increase. With proper management of traffic and demand, the road network will not be subject to the capacity and related serious environmental problems observed in almost all large cities of the world.

The present quality of life in Islamabad is made apparent from the satisfaction expressed by the people who live and work there and by the wish of others to reside in the new city. Islamabad is a "unique" example of a large new city "planned for the future and built for the present", fully respecting the long-term planning.
\end{abstract}

Keywords: urban planning, sustainable city, sustainable transportation, new cities. 


\section{Introduction}

Traffic congestion in urban areas and related environmental problems such as air/noise pollution, through car movements in residential and other sensitive areas, road accidents, etc. are mainly due to the development of these areas before the explosion of car ownership as well as to the lack of proper combined transportation-land use planning, to cope with this explosion.

Efforts are being made to obtain sustainable mobility through proper traffic and demand management, improving Public and other "Green Modes" of transport, using Intelligent Transportation Systems, etc. Parallel efforts are being made to convert the existing road network into a system of properly spaced arteries, collectors and local roads, each category serving the proper through and access movements generated by the existing and planned land uses. However, the limitations imposed by the existing road pattern do not allow for the development of the proper configuration, spacing and capacity of the road network required. As a result, the ever increasing traffic imposes its rules. When existing as well as possible new arteries are saturated, new arterial routes are created through collector and local streets within residential areas, deteriorating the quality of life and increasing traffic accidents in these areas $[1,2]$.

In new cities, there is a chance to achieve sustainability through proper combined transportation-land use planning, based on the proper modes of transport and expected future developments. Often, this opportunity is not fully exploited. Furthermore, no detailed evaluations of new cities have been carried out to quantify the effects of the application of new planning principles.

Islamabad is a remarkable example of a new city where the concept of "sustainability", although the particular term was not used at the period of its planning, was applied to create a "City of the Future". Planned in the period, 1959-63 on the basis of "Ekistics", Doxiadis" "Science of human settlements", Islamabad is being developed fully respecting the "Doxiadis Plan" as the Pakistanis refer to the Master Plan and other related studies on which the implementation is based [3].

\section{The Islamabad example}

\subsection{The birth and location of the capital}

A new capital for Pakistan was necessary following the independence of India in 1947 and the inevitable partition into India and Pakistan. Various solutions were proposed for the location of the new capital from 1947 to1959 when the final decision was reached. The two most important were related to the creation of the new capital, either in Karachi or at a distance of about 15-20 miles from this city. In February 1959, the government decided to investigate the problem in a more thorough way. A commission and nine sub-committees were formed [4].

C.A. Doxiadis started advising on the location and planning of the new capital in 1955 when he submitted his first report. In March 1959 the president of Pakistan named C.A. Doxiadis adviser to the special commission investigating 
the problem of the location of the new capital. He proposed a site he visited in the summer of 1959, which was finally approved. The approved site is located at the foot of the Margala hills in northern Pakistan between the historical cities of Lahore and Peshawar, west of the Idaspis (now Jhelum) river where Alexander the Great defeated king Poros.

\subsection{The hierarchical concept in communities, land uses and transportation system}

Islamabad is planned according to a hierarchical system of communities of various classes, each class comprising the functions corresponding to its size. These communities are properly served by a major transportation system developed within wide corridors of a grid-iron configuration, surrounding and defining the higher class communities. Local and collector low speed roads, wide sidewalks, pedestrian roads and bicycles lanes within the lower class "human communities" provide access to the major transportation system. The above hierarchical system of communities and transportation facilities, contributes to the reduction of travel distances/times and accidents, and to the promotion of "green transport" (walking, cycling, public transport).

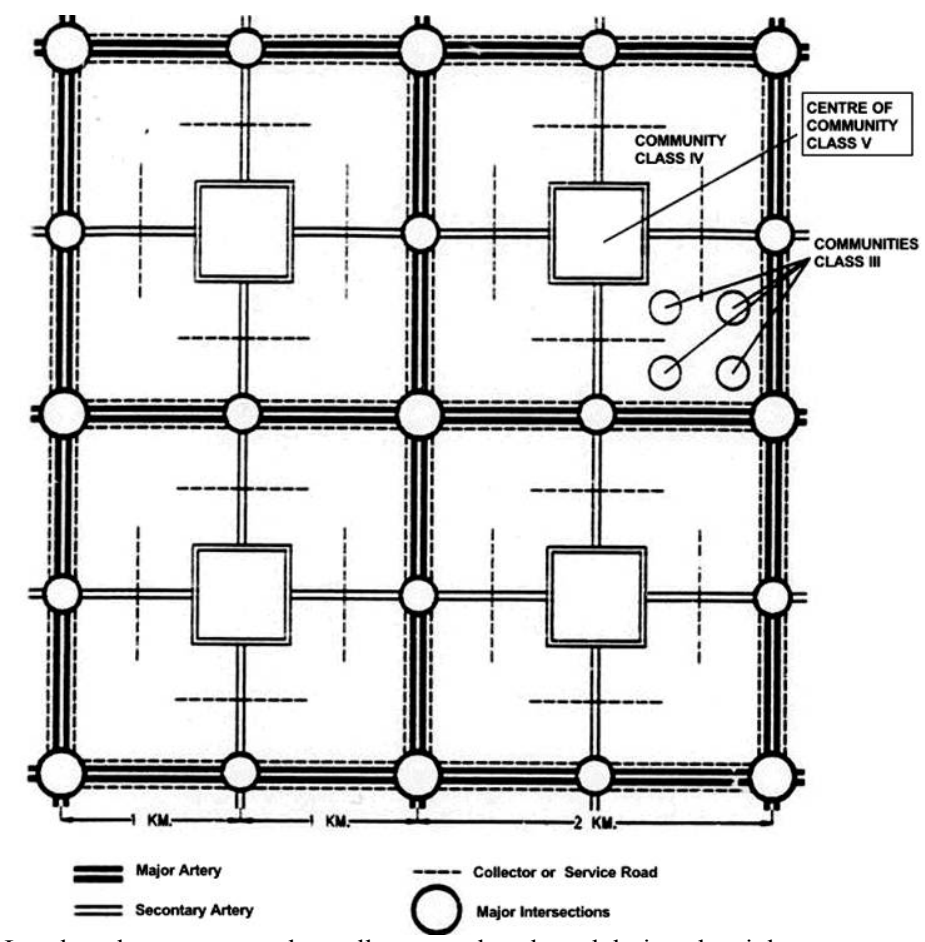

Local roads are connected to collector roads only and designed mainly as cul-de-sacs or loops.

Figure 1: Schematic representation of the hierarchical pattern of communities and transportation [1]. 
Figure 1 gives a schematic representation of four Class V Communities. Each Class V Community has a population of 20.000 to 40.000 inhabitants and is divided into four Class IV communities, each composed in turn of four Class III Communities. Class V communities are spatially defined and accessed by major arteries at $2 \mathrm{~km}$. intervals. These arteries may be gradually upgraded to freeways, depending on increasing traffic flows. They are developed within $180 \mathrm{~m}$ wide transportation corridors where high speed public transport may also be accommodated.

Short length minor arteries (190m R.O.W.) are spaced at about $1 \mathrm{~km}$ distances, defining Class IV communities within which pedestrians can safely walk along a system of local roads, wide sidewalks and pedestrian roads, leading to the local centres and functions. By the extensive use of cul-de-sacs and loops, cars can move inside these "human communities" without interfering with pedestrians.

\subsection{The master plan and the dynametropolis concept}

The Islamabad Metropolitan Area is composed of Islamabad, the old city of Rawalpindi and the National Park. The latter is a hilly area, containing two large lakes, the National Sports Centre, the National University and the National Research Centre. Four major interurban roads delineate the above three major components of the Metropolitan Area (fig. 2.)

The overall plan is based on the "dynametropolis" concept, giving the possibility of continuous expansion with the least possible adverse effects in traffic and, generally, in the functioning of the Metropolis. Both Islamabad and Rawalpindi, central cores and residential areas, may expand dynamically (figs. 2, 3).

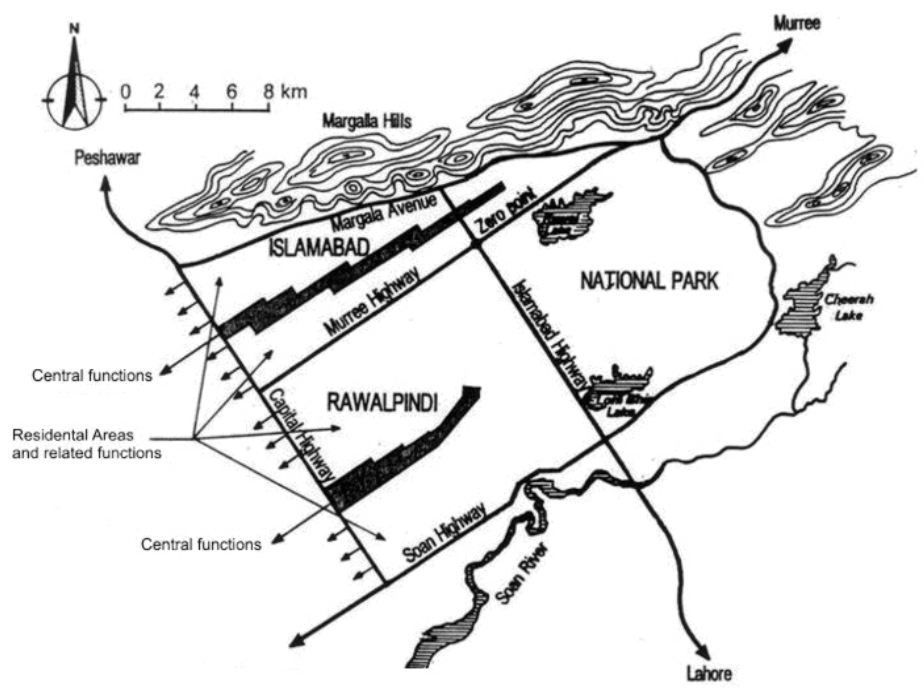

Figure 2: $\quad$ Islamabad Metropolitan Area. The concept of the dynametropolis [5]. 


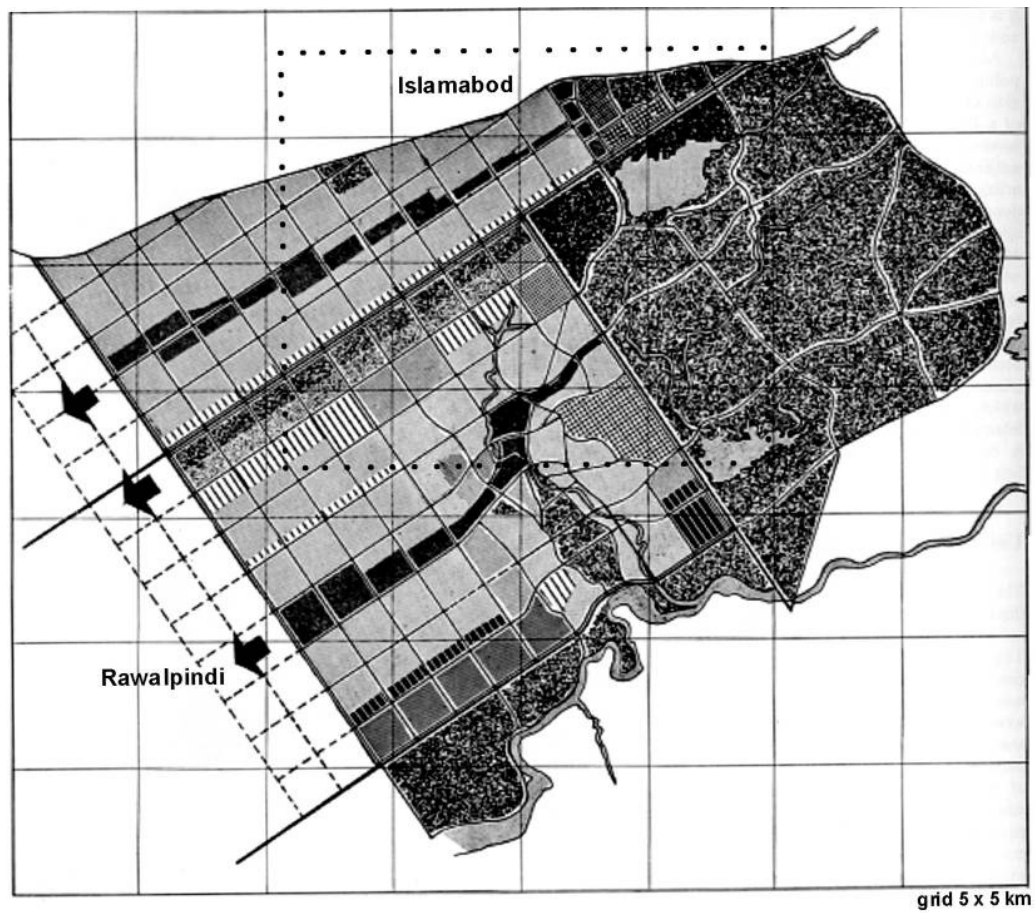

Figure 3: The master plan of the Islamabad Metropolitan Area.

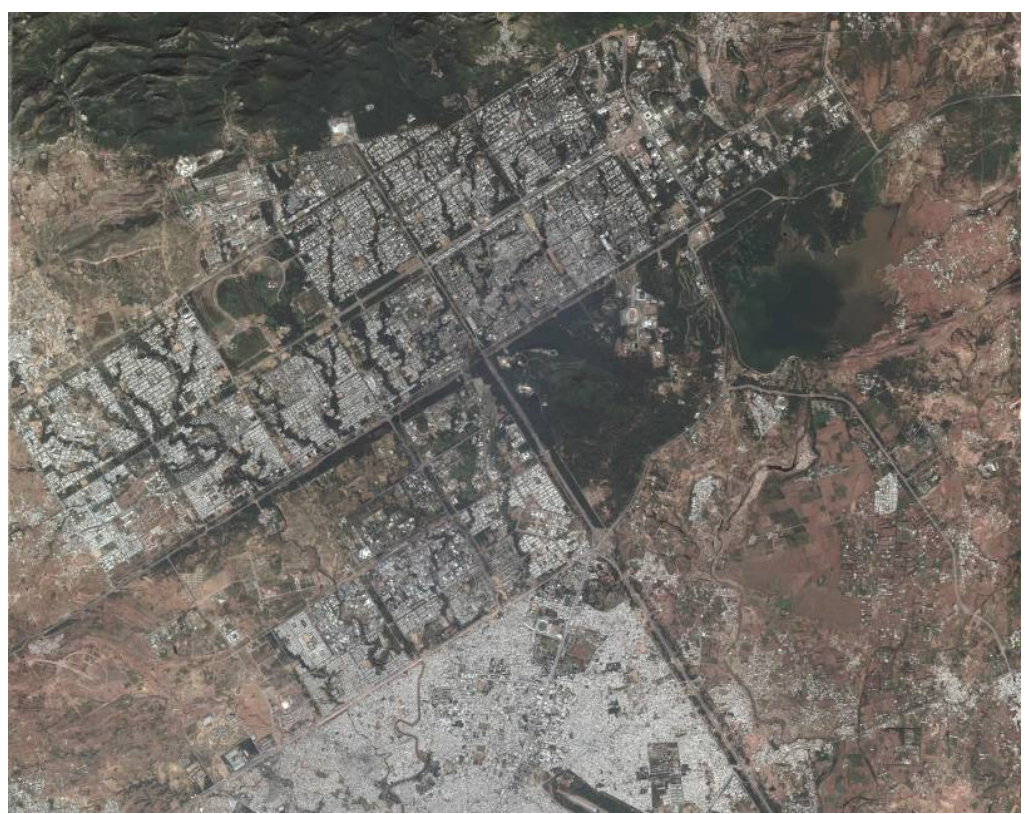

Figure 4: $\quad$ Recent aerial view of Islamabad [9]. 


\subsection{The present situation}

The Metropolitan Area of Islamabad has today a total population of some 4.5 million inhabitants, 1.5 million in Islamabad and 3.0 million in Rawalpindi (fig 4). Photographs of roads and centres of various classes are given in Figures 5-10.
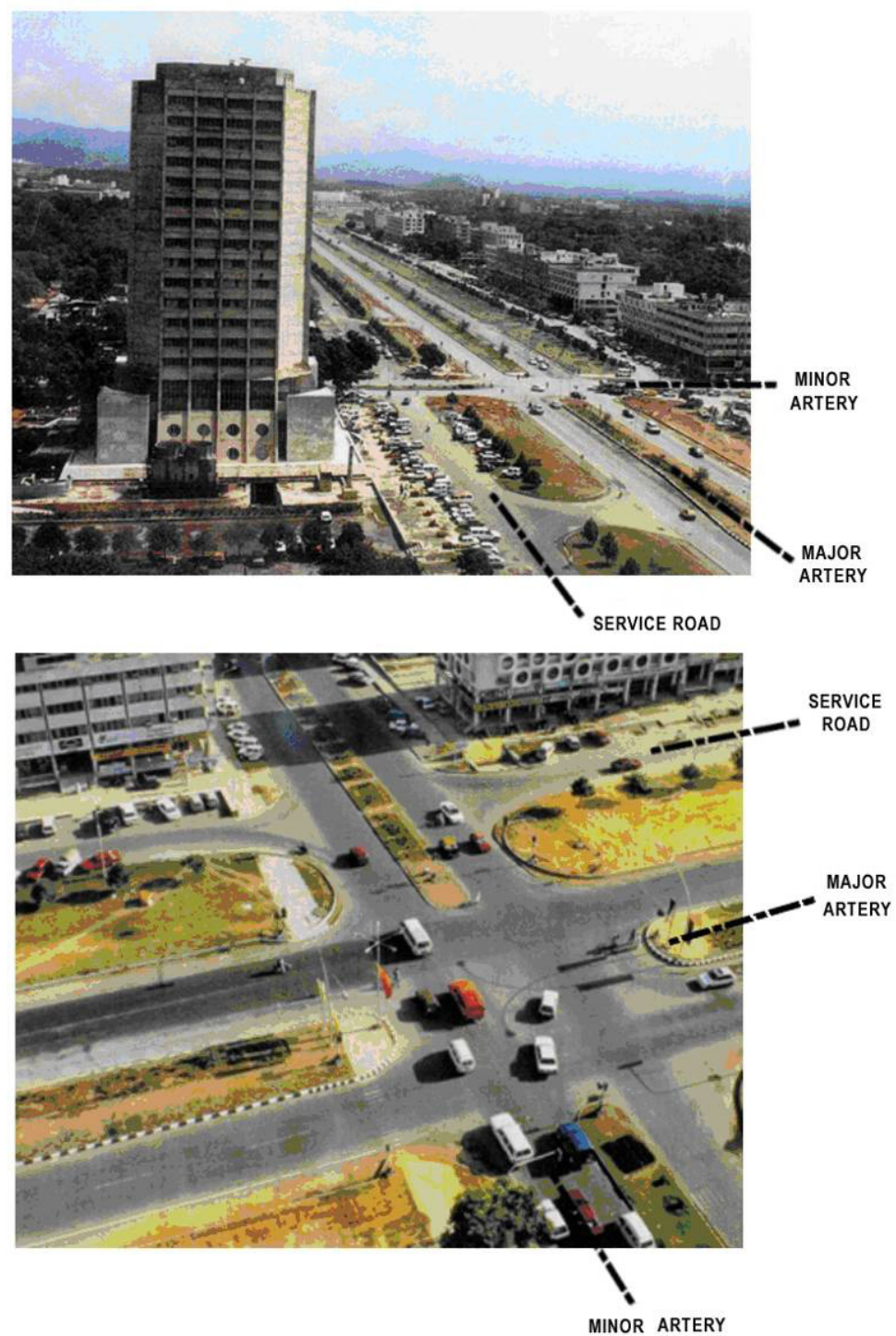

Figure 5: $\quad$ Intersection of a major and a minor artery [6]. 


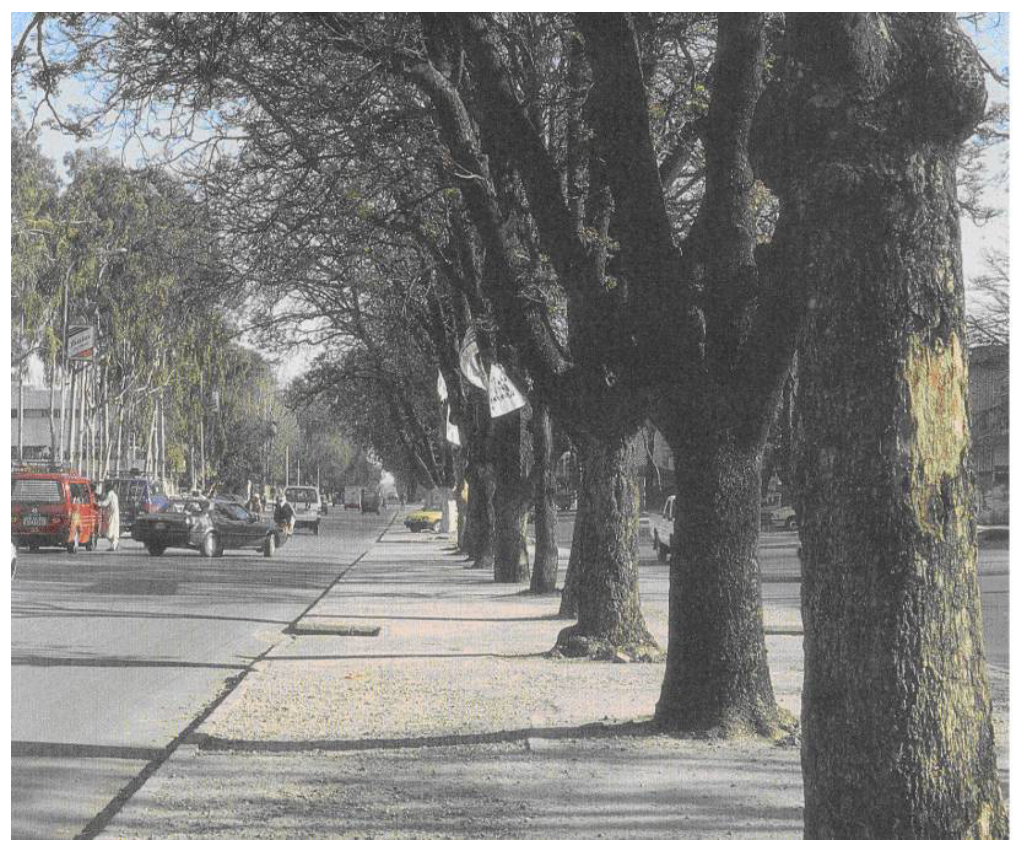

Figure 6: Collector road [6].

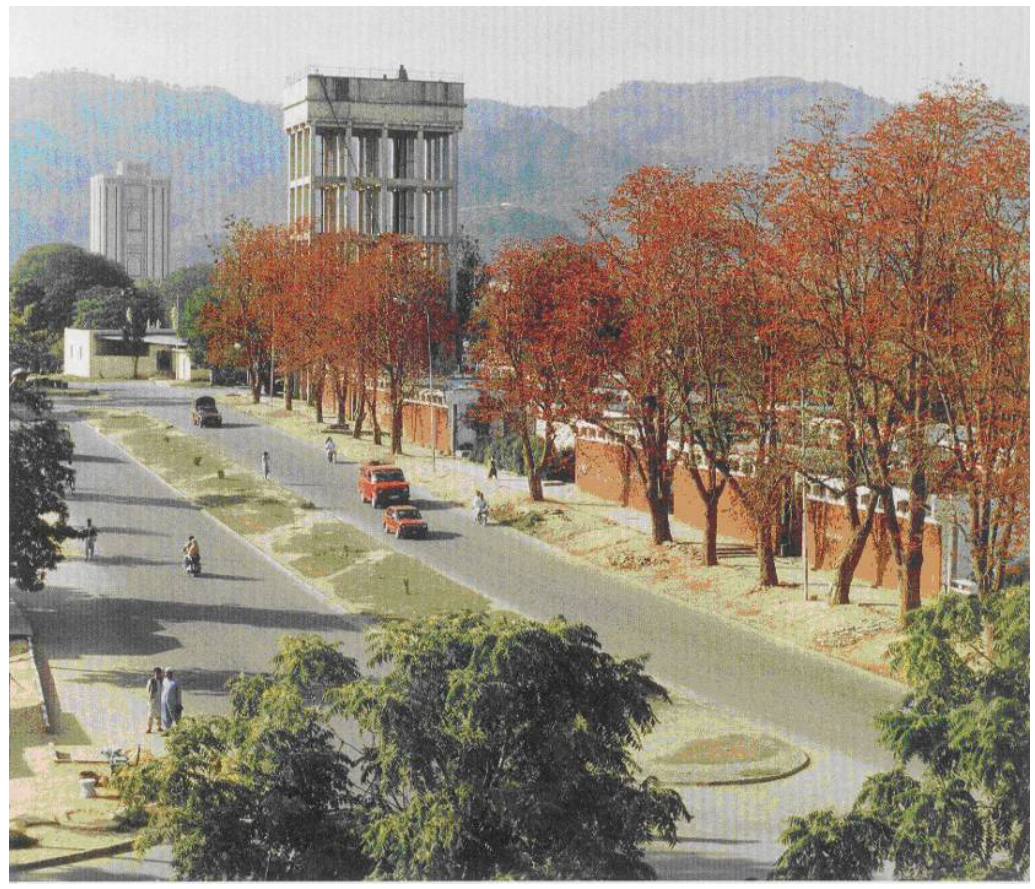

Figure 7: $\quad$ Local road [6]. 


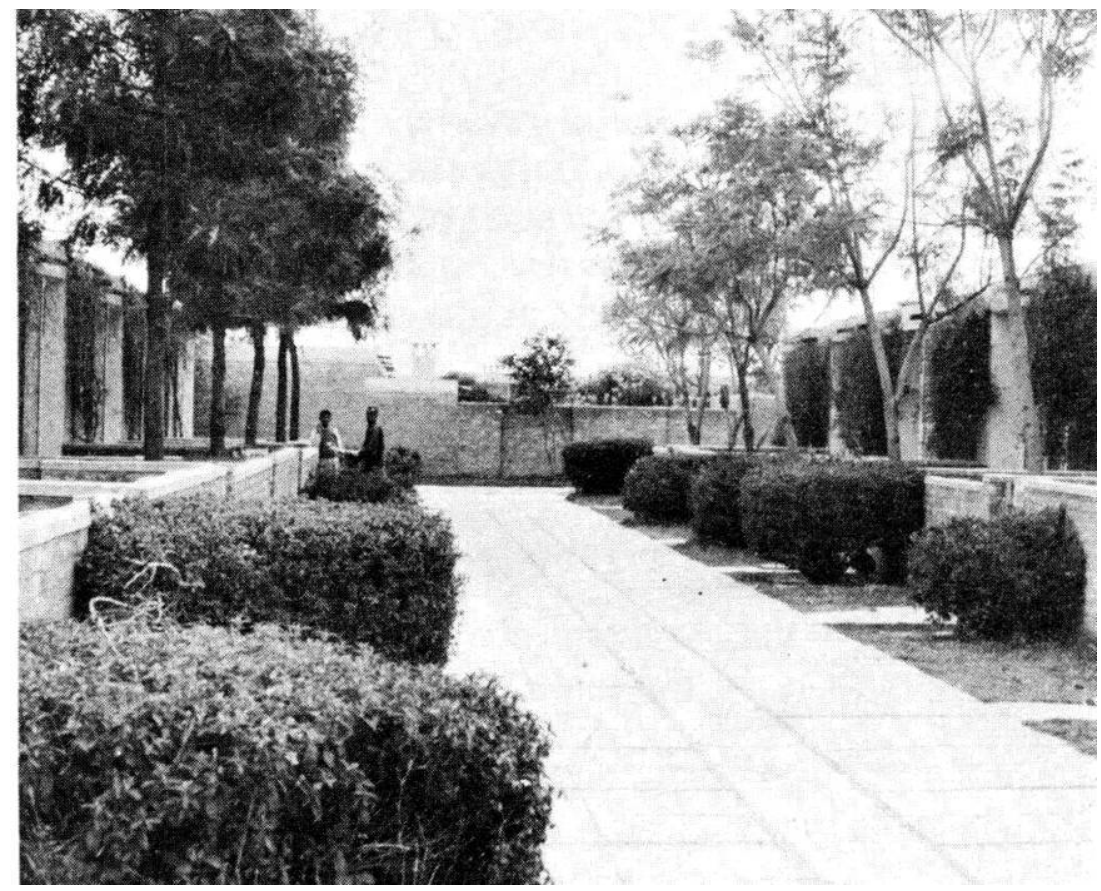

Figure 8: $\quad$ Pedestrian road in a low-income residential area [4].

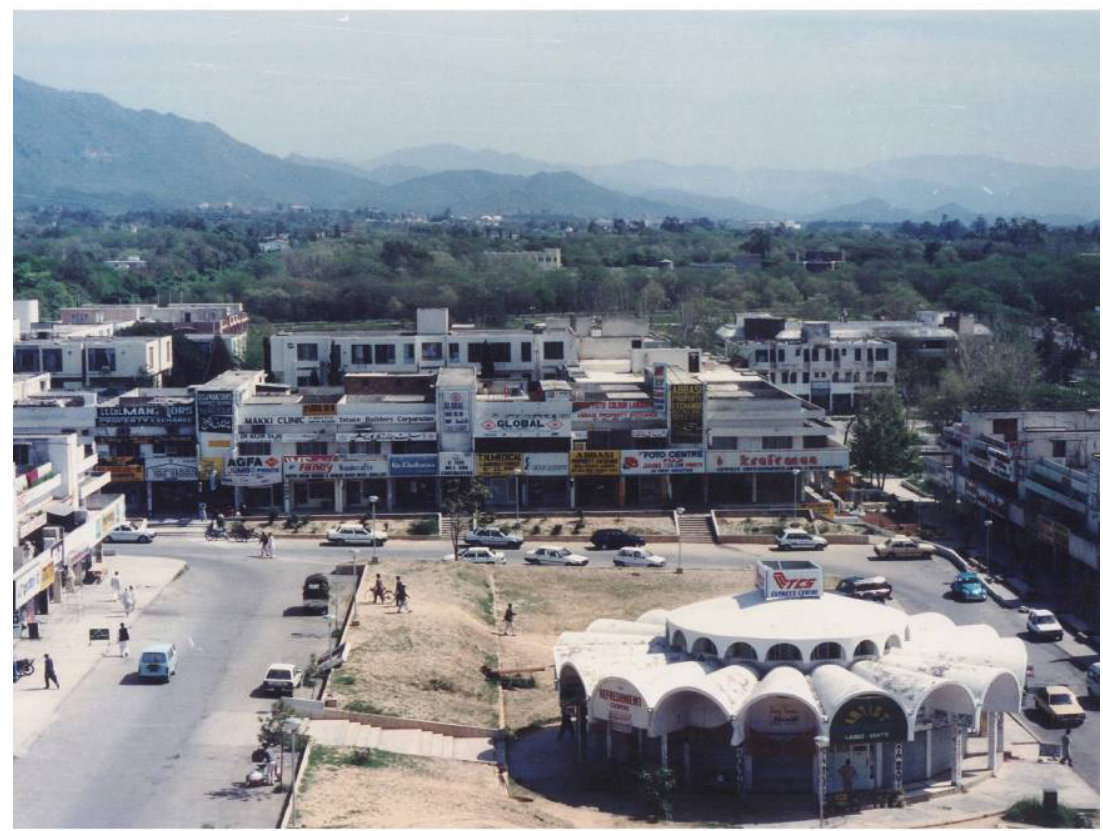

Figure 9: $\quad$ Community class V centre [6].

WIT Transactions on Ecology and the Environment, Vol 120, (C) 2009 WIT Press

www.witpress.com, ISSN 1743-3541 (on-line) 


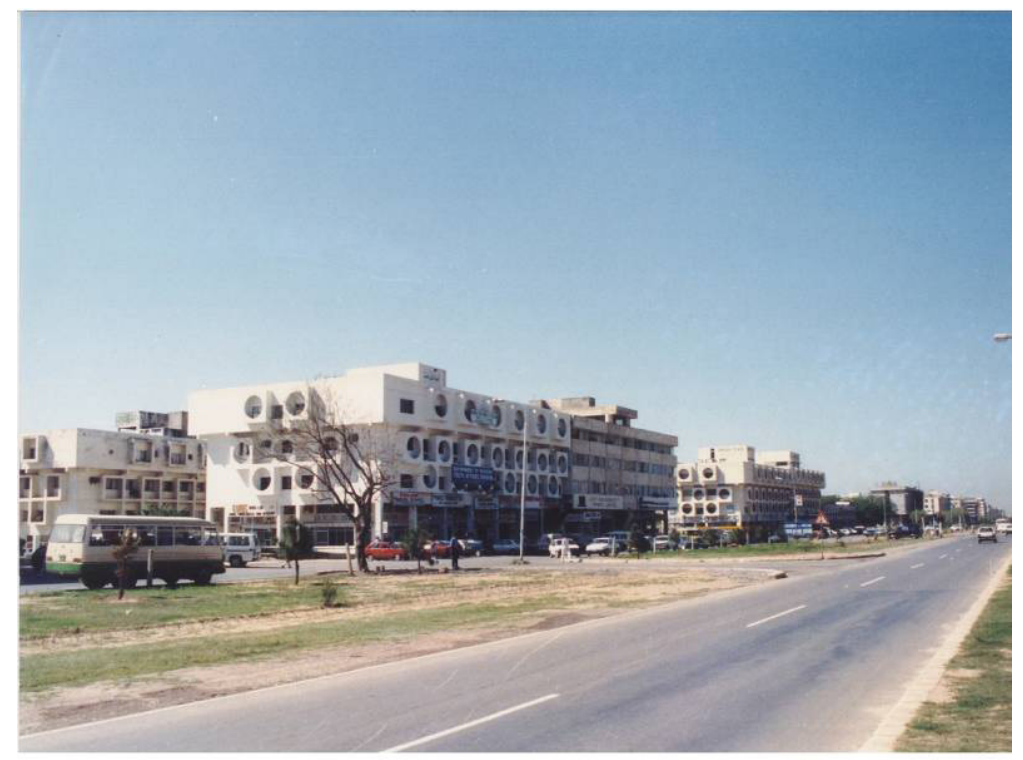

Figure 10: Linear commercial/business centre [6].

\section{Conclusions}

While special research on comprehensive planning of land use and transportation is carried out during the last years, e.g.: LUTR (Land Use and Transport Research) of the $5^{\text {th }}$ Framework Programme of the EU, no analytical evaluation of the results of planning new cities or large extensions of existing cities is carried out. Islamabad, the new capital of Pakistan, gives an opportunity to carry out such an extensive research.

The Islamabad-Rawalpindi-National Park metropolitan area is at present a 4.5 million inhabitants urban development, comprising the new capital $(1.5 \mathrm{~m}$. inh.) and a large extension of the neighbouring city of Rawalpindi (3.0m. inh.) i.e. ten times the population of 1960, when the construction of the new capital started.

"Planned for the future and built for the present", the Metropolitan Area of Islamabad is a "Dynametropolis" which presents the following basic advantages:

a. The possibility of a dynamic extension of both the residential areas and related functions and the various central functions (Administration, Industry, Recreation etc).

b. The final dimensioning of the various elements of the city from the start, thus securing the location and size of the required land (e.g. 180m R.O.W. for the major transportation corridors and $90 \mathrm{~m}$ for the minor ones) while the construction is phased depending on the increasing needs.

c. A Master Plan that reflects the needs of the physical environment to an increasing degree, starting from the straight line alignment of the 2 by $2 \mathrm{~km}$. grid iron system of the major transportation corridors down to the 
forms of local elements, i.e. local roads with small radius curves, dead ends and loops, pedestrian roads with stairs, etc.

d. A hierarchy of communities and functions, from a "neighbourhood" of a few inhabitants to large communities of some thousands of inhabitants, each one with functions proper to its scale (market, schools, office buildings, recreation, green areas, etc.) reduces trip-lengths and increases safety and convenience of movements. Combined with the proper hierarchy of roads and other transportation facilities, the above hierarchy of communities and functions segregates the various length and speed movements. People are directed to the proper transportation facilities, while long high speed through movements are kept away from the lower classification "human communities"

The above advantages are made apparent from the satisfaction of people who live and work in Islamabad and by the wish of other Pakistanis to reside there. They will be more and more apparent as the urban area expands and its population and car ownership increase. With a proper management of traffic and demand, the road network will not experience the capacity and related serious environmental problems observed in almost all large cities of the world. Nevertheless, a transportation study conducted in 1994-5 has pointed out traffic problems created by improper behaviour of road users, (lack of respect to traffic lights, to lanes for opposing traffic, etc), by the public transport drivers (stopping anywhere to drop and pick up passengers), by improper design and signage of intersections, by lack of systematic police enforcement, etc.

Unfortunately, no detailed research, quantifying the effects of the planning principles applied in Islamabad has been carried out so far. Such research, comprising meaningful comparisons with other Metropolitan Areas as well as other New Cities, would greatly contribute to the proper understanding of planning and operation requirements for a truly sustainable city.

\section{References}

[1] Frantzeskakis J.M., Configuration, Hierarchy and Spacing of the Urban Road Network in Islamabad, Ekistics, No 373-75, pp. 236-241, JulyDecember 1995.

[2] Frantzeskakis J.M., Butt N.A., Planning Urban Networks: The Islamabad Example, Traffic Quarterly, Eno Transportation Foundation, Inc. Lands dame, Virginia, Vol 51, No1, pp. 101-110, winter 1997.

[3] Mahsud Ahmed Zaib K., Constsntinos A. Doxiadis' Plan for Islamabad: The Making of a "City of the Future" 1959-63, Thesis submitted to the Catholic University of Leuven, Belgium as partial fulfilment for the degree of Doctorate in Applied Sciences/Engineering: Architecture Urbanism and Planning. Book I, Book II. April 2008.

[4] Yakas O., Islamabad: The Birth of a Capital, Oxford University Press, 2001.

[5] Islamabad: Symbol of a Nation. A D.A. project revisited. Doxiadis Associates Review No 68, August 1970. 
[6] Capital Development Authoring (CDA), Islamabad the Beautiful, Islamabad Directorate of Public Relations, CDA, 1995.

[7] National Transport Research Centre, Government of Pakistan, Contrans AB, Greater Islamabad/Rawalpindi Area Transportation Study (GIRATS). Final Report, September 1995.

[8] Frantzeskakis J.M., The influence of C.A. Doxiadis Principles on Urban Transportation \& Traffic. Proceeding of the Conference: Constantinos A. Doxiadis and his Contribution, January 19-21, 2007 Athens, Technical Chamber of Greece, 2008.

[9] Google earth. Satellite photos 2005-8. 